\title{
JOINTING OF HIGH-LOADED COMPOSITE STRUCTURAL COMPONENTS. PART 1. DESIGN AND ENGINEERING SOLUTIONS AND PERFORMANCE ASSESSMENT
}

\author{
Ya. S. Karpov
}

UDC 624.078 .4

The author presents and discusses the results of investigation to verify the design principles for jointing composite components. Based on the findings, novel design and engineering solutions for metal-composite joints are put forward. To ensure an effective transition from a composite material to a metal butt-joint fitting, new jointing techniques have been developed involving the use of embedded longitudinal and transverse fastening microelements in a composite material, which are molded into or mounted on a metal component. A modification of half-stitch jointing is proposed which enables the joint to work in compression and reduces the pressing stresses in the winding zone. Based on the study of force transfer conditions in the proposed joint design and the jointing solutions, the author defines the main lines of theoretical and experimental investigations to support the engineering and stress analysis activities. The experimental static strength assessment demonstrates effectiveness of the proposed solutions.

Keywords: jointing, composite material, fastening element, design and engineering solution, design principle, strength, experiment.

Introduction. At present, composite materials (CM) have found extensive applications in almost every manufacturing industry. Despite numerous problems relating to mechanics, strength, design and manufacturing of composite structures are important and have to be solved, it can be stated that the most significant task is to develop design and engineering solutions (DES) for jointing high-loaded components of fiber-reinforced composites. When composites were used to make some auxiliary or low-loaded structural members, mechanical fastening and adhesive bonding were quite efficient.

However, as the necessity of designing and manufacturing heavy-duty $\mathrm{CM}$ assemblies, especially in the aerospace industries has arisen, the problem of jointing has gained in significance for the following reasons:

- The use of conventional mechanical fastening and methods of its installation leads to cutting of a considerable portion of fibers, which requires certain compensation and revision of the CM structure.

- Adhesive bonding of high-loaded components under large-scale production conditions is difficult to implement because of stringent requirements for process parameters and workmanship, lack of reliable nondestructive testing methods, impracticability of repair, and design engineers' doubts about adhesive bonded joints, especially if such joints are critical for the product safe operation; polymeric composites have lower bearing, shearing, and interlaminar shear strength characteristics. The reported bearing strength values of 400 to $700 \mathrm{MPa}$ [1-8] were obtained on very thick laboratory specimens where the influence of the scale factor greatly decreases.

- Machining of up-to-date composites is a difficult and expensive process that requires advanced cutting tools and equipment $[2,9-11]$. The problems of standardization, assurance and monitoring of hole accuracy and machined surface quality are still to be solved.

Zhukovskii National Aerospace University "Kharkov Aviation Institute,” Kharkov, Ukraine. Translated from Problemy Prochnosti, No. 3, pp. 23 - 33, May - June, 2006. Original article submitted September 5, 2005. 


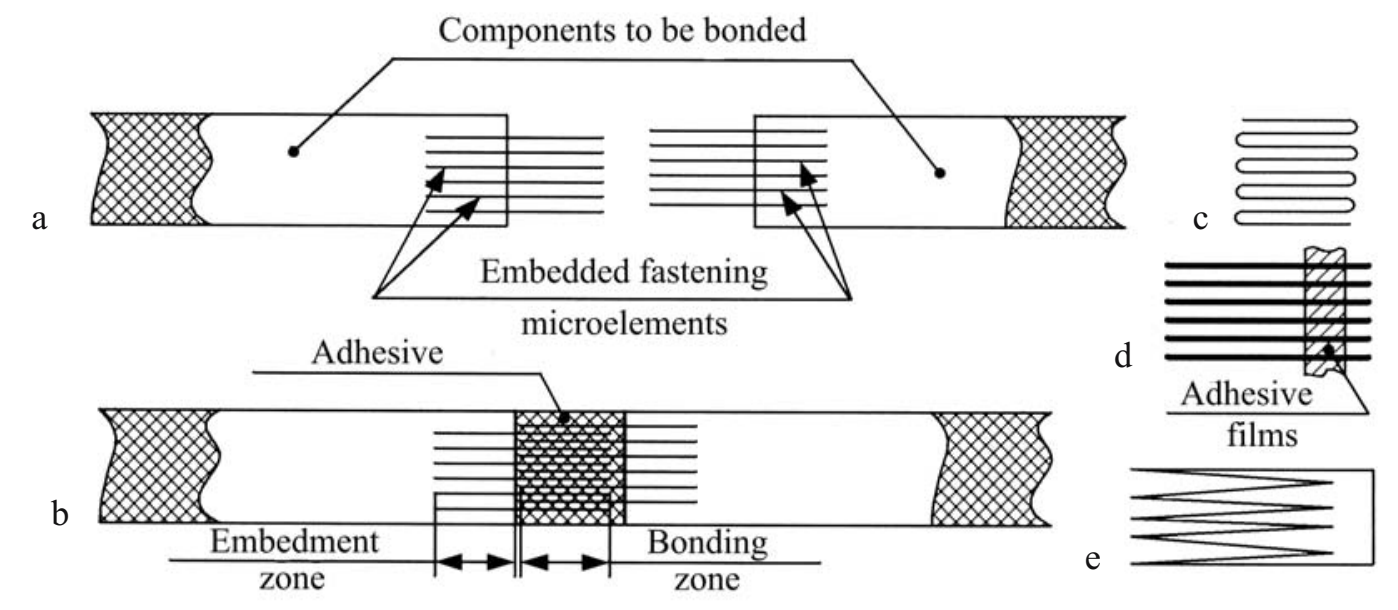

Fig. 1. A method of jointing by means of embedded longitudinal fastening microelements.

Two main trends to tackle the jointing problems are pursued now:

(I) improve the conventional (mechanical fastening and adhesive bonding) jointing methods considering the special features of composites and the processes of their re-designing; this includes research efforts aimed at employing small-size fastening [2,12-16], development of composite fastening members [9, 13], search for means of raising bearing and shearing strength characteristics of composites [17-19], etc.;

(ii) search for fundamentally novel design and engineering solutions for jointing, which would be organically peculiar to structures made of composites. This way seems to be a more advisable one and in many cases it has resulted in the development of quite efficient joints: half-stitch connecting tips [20-24], stepped adhesive bonded joints [25-27], polymer-to-metal matrix transition in the interface area with fibers remaining continuous [28], etc.

The investigations of main types of failures of conventional joints and the search for methods of improving the joint strength characteristics [29-31] have made it possible to formulate the following jointing design principles:

- the reinforcement should remain intact during the CM-metal jointing;

- the forces from the smallest possible CM volume (in the limit, from every thread, fiber) should be relieved (transferred) in the reinforcement direction;

- the fastening members should be miniaturized and repeatability of their installation quality should be ensured for implementation in large-scale production;

- the intermediate (transitional) CM-metal joints should be integrated into the CM structure during its formation.

Design and Engineering Solutions for CM Jointing. The principles listed above have been implemented in the new design and engineering solutions developed and tested by Zhukovskii National Aerospace University "Kharkiv Aviation Institute." Figure 1a, b illustrate a jointing method which involves the use of longitudinal fastening elements made of metal wire or boron fibers and embedded in a CM workpiece. After workpieces have been molded, their free wire (fiber) ends are aligned through mutual overlapping and the bonding zone is then impregnated with an adhesive compound [32]. Considering the large quantity of fastening elements (about 40-60 vol.\% in the bonding zone) it is advisable to prepare them in the form of some intermediate products, such as zigzag bent wire (Fig. 1c), adhesive-film-bonded wire layers (Fig. 1d), stamped metal foil blanks (Fig. 1e), etc.

The joint made by means of longitudinal fastening elements (Fig. 1) is based on their adhesion in the bonding zone as well as in the embedding zone in the CM. The pulling-out force measurements demonstrate that the wire rupture occurs when the embedment length is more than $10 \mathrm{~mm}$. These data are supported by the strength test results for carbon-fiber-reinforced plastic (CFRP) joints with various bonding zone lengths $l$ (Figs. 2 and 3).

To test the performance of high-loaded CM joints, we prepared CFRP $\left(\left[0^{\circ}{ }_{60}, \pm 45^{\circ}{ }_{3}, 90^{\circ}{ }_{4}\right]\right.$ structure $)$ specimens with a cross-sectional area of $400 \mathrm{~mm}^{2}(8 \times 50 \mathrm{~mm})$, so that there was no force in the transitional zone to the tip. 


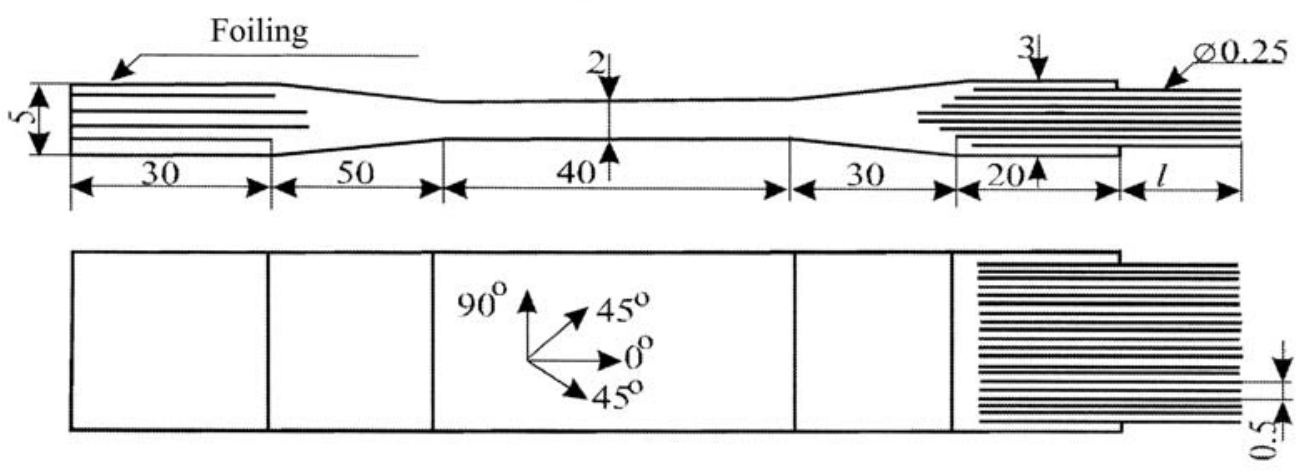

Fig. 2. Joint samples with longitudinal fastening elements.

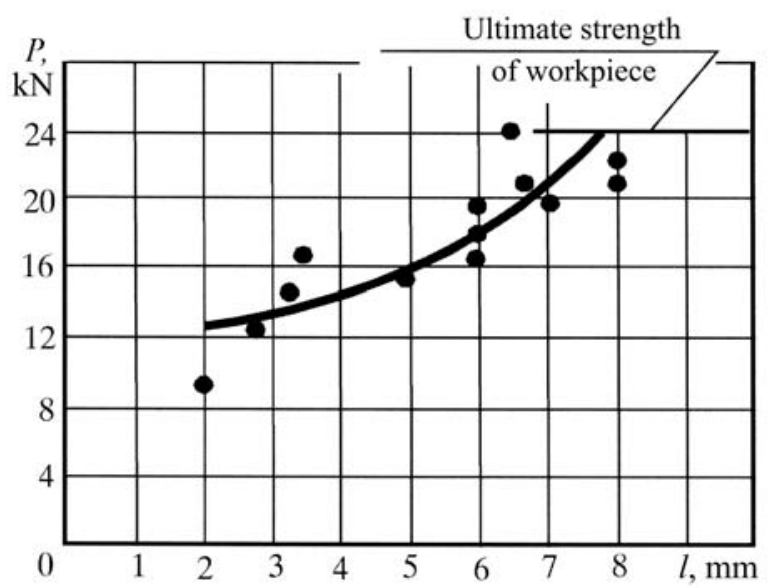

Fig. 3. Joint strength as a function of the bonding zone length (solid line - approximation, dots - experimental data).

The joint was designed to withstand loads up to $200 \mathrm{kN}$ and each of the components contained 2000 longitudinal fastening elements made of 0.25 -mm-diameter steel wire. The static test results are summarized in Table 1.

Analysis of the experimental data has demonstrates that (a) with a bonding zone longer than $10 \mathrm{~mm}$ the joint has survived thus suggesting the great potential of this DES, and (b) the transition zone to the connecting tip, where warping of CM fibers is inevitable, should be additionally strengthened. This conclusion is based on the fact that the sharpened fastening elements installed on a metal connecting patch penetrate into the prepreg after the CM layers have been stacked up, and the co-polymerization of the binder is carried out (Fig. 4) [33]. This method of placing the fastening elements preserve the integrity of $\mathrm{CM}$ fibers and ensures identical conditions for interaction between $\mathrm{CM}$ and the fastening elements.

Figure $4 \mathrm{~d}-\mathrm{f}$ illustrates the possible ways of how to install the fastening elements by molding, welding and milling, while Fig. $4 \mathrm{~g}$, $\mathrm{h}$ show the possible arrangement of the elements on the patch surface. The shape and dimensions of the patch (fitting) may vary depending on the joint designation and the mating assembly configuration.

To assess the performance of the joints involving transverse fastening elements, several types of specimens were designed, manufactured and tested on the basis of the experimental data given above. The workpieces of the first set were made of CFRP $\left(\left[0_{60}^{\circ}, \pm 45^{\circ}{ }_{3}, 90^{\circ}{ }_{4}\right]\right)$ with a cross-sectional area of $400 \mathrm{~mm}^{2}(8 \times 50 \mathrm{~mm})$ and were fitted with tip consisting of two 8-mm-thick patches of D16AT alloy. Each patch had 120 1-mm-diameter steel pins embedded in it with 7-mm spacing along the joint and 4-mm spacing across it, so that a uniform pin distribution in $\mathrm{CM}$ would be achieved during their molding into the composite. The fracture of five specimens without any strengthening in the joint zone occurred on the first/second row of the fastening elements with a margin of safety 0.78 . 
TABLE 1. Static Test Results for CFRP Joint Specimens with Longitudinal Fastening Elements

\begin{tabular}{||c|c|c|c||}
\hline Specimen No. & Bonding zone length, mm & Breaking force, $\mathrm{kN}$ & Failure mode \\
\hline 1 & 15 & 90.3 & Tip fracture in specimen grips \\
2 & 10 & 160.7 & Ditto \\
3 & 18 & 176.0 & Fracture in the transitional zone to the connecting tip \\
4 & 12 & 187.3 & Ditto \\
5 & 10 & 111.2 & Joint fracture due to poor adhesive impregnation \\
6 & 10 & 201.5 & Fracture in the transitional zone to the connecting tip \\
\hline
\end{tabular}

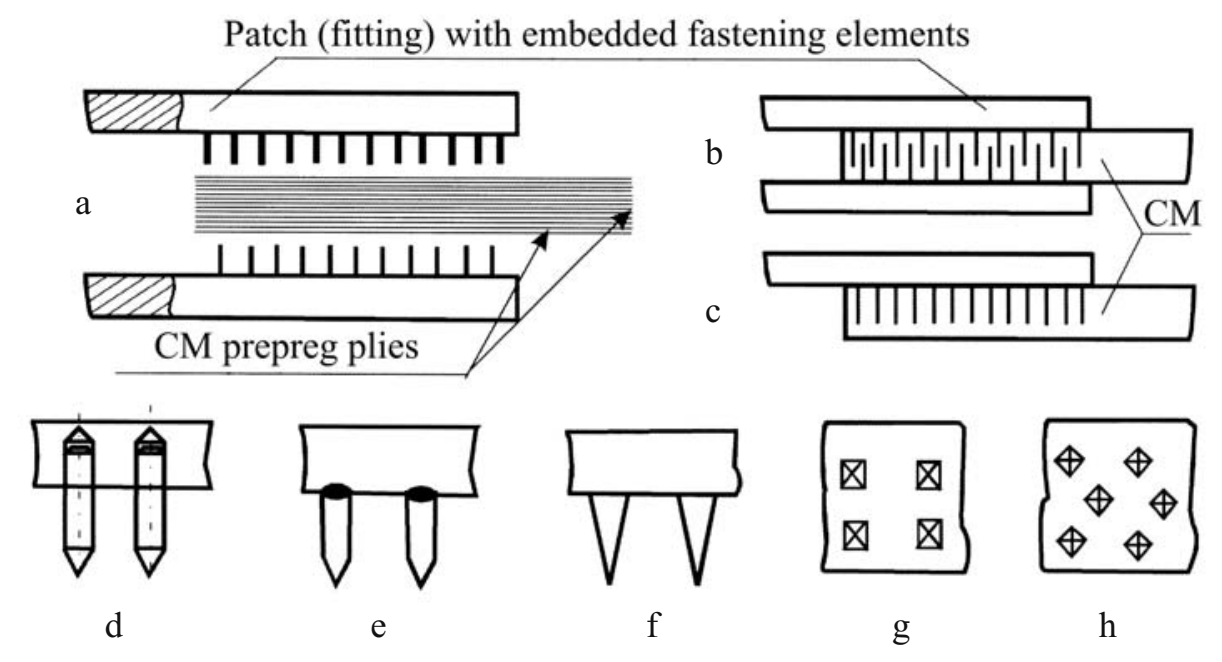

Fig. 4. Design and engineering solution for jointing by means of embedded transverse fastening microelements.

The design and engineering solution for jointing by means of transverse fastening microelements holds the greatest promise for CM laminate applications. Therefore, all the aspects of strength of the joint and its elements will be addressed in detail in the follow-up report.

The benefits and drawbacks of a conventional half-stitch joint formed by enveloping a butt bolt with CM threads (Fig. 5a) are well known. To ensure taking up the compressive forces it was suggested that the central bolt (pin, axle, etc.) should be fitted with additional washers (Fig. 5b, c), fins (Fig. 5d) or transverse fastening microelements (Fig. 5e) to which the CM was adhesively bonded during polymerization.

For the static strength testing of this joint we prepared, through winding, unidirectional-reinforcement CFRP specimens with a cross-sectional area of $400 \mathrm{~mm}^{2}$ (two strands $30 \times 6.6 \mathrm{~mm}$ ), with 1 -mm-spaced stainless steel washers. The fracture load was $150 \mathrm{kN}$ in tension and $160 \mathrm{kN}$ in compression. In the tensile tests the fracture occurred near the washers, while in the compression tests the fracture was due to washer breaking and crushing.

We studied also various process modifications for this specific type of winding in order to ensure the most uniform possible tension of all the layers prior to polymerization. The best outcome has been provided by the process where the center-to-center distance (initial value being $250 \mathrm{~mm}$ ) decreased by $0.3 \mathrm{~mm}$ upon each layer and the initial distance was restored after all the layers had been wound up.

As follows from the above description of new design and engineering solutions, their objective has been to provide an efficient transition from a composite material to a metal fitting. A complex metal-composite heterogeneous structure (MCHS) is formed in the transitional zone, and the efficient implementation of the MCHS design principles as stated above will depend on the ratio of parameters of the components. A comparison between the proposed DES and the conventional jointing methods has demonstrated that for the stress analysis and design a special complex of computation and experimental means should be elaborated since most of the available data for conventional jointing DES are almost non-applicable to the determination of MCHS parameters. 


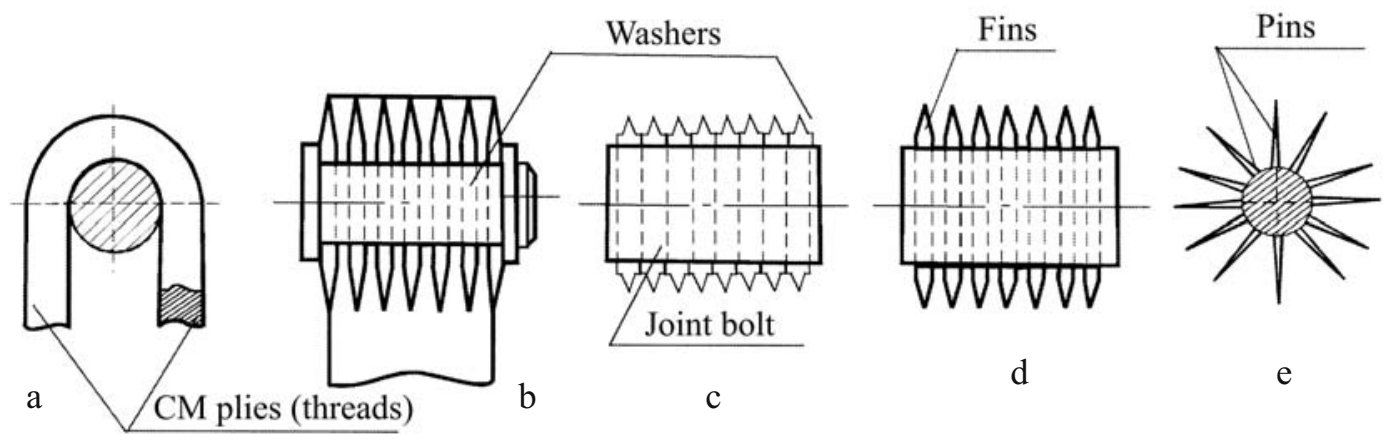

Fig. 5. Modified half-stitch jointing.

The Extent of Theoretical and Experimental Means for Stress Analysis of Joints. The stress analysis and design of joints are based on mathematical models for the determination of a stress-strain state (SSS). To enable a comparison of relative efficiency of various DES, it is advisable to have the SSS assessment techniques that are based on analytical models of the same level, i.e., provide equivalent conditions for comparing the objective functions of design. Analysis of numerous theories and techniques suggests that none of them can describe (model) all the possible joint DES, except for the finite-element method although it too is poorly suited for the design purposes. Furthermore, the stress analysis requires specific data on the conditions of interaction between MCHS components.

The main distinctive feature of a MCHS with transverse fastening elements (Fig. 4) is that small-sized pins are enveloped by continuous fibers (threads) and therefore the SSS calculation requires quantitative data on the variation of $\mathrm{CM}$ elastic properties in the volume of the joint. The great variety of shapes, dimensions and arrangement of fastening elements as well as structures of composites to be bonded dictates makes it necessary to define theoretical and experimental relationships for the determination of compliance coefficients of fastening elements and components to be jointed. The available techniques and setup for experimental determination of these parameters need serious revision.

A similar problem is encountered where the bearing strength of a $\mathrm{CM}$ is to be determined. The bearing strength was experimentally demonstrated [1,3,35-37] to depend on the size of fastening elements and the CM structure. In this context, it would be advisable to develop new methods and devices for the bearing strength testing of $\mathrm{CM}$, especially considering that the design and engineering of an assembly (part) have to address various CM structures, fastening element coatings, manufacturing process variables, i.e., all the factors that are difficult to include in analytical models and techniques.

An important parameter involved in the stress analysis of joints with transverse fastening (Fig. 4) is the factor of CM strength degradation in the element embedment and molding zones, which can be interpreted as some analog of the classical stress intensity factor. Although no fiber shearing occurs in the proposed DES, the bending of CM reinforcement and the change of its volume content result in degradation of the material bearing capacity. A study of strength of composites with embedded inclusions will make it possible to substantiate rational dimensions, shape and arrangement of fastening elements.

The additional reinforcement of a CM tip with longitudinal fastening elements poses a problem of physico-mechanical characterization of the hybrid CM tip and the tip transitional zone, since the design parameters of this structure are as follows: the element arrangement pattern in CM, embedment depth, allowable change in volume content of CM components, and an optimal value of the volume content of fastening microelements in the bonding zone (Fig. 1).

The main task for a modified half-stitch joint is to ensure controllability of the CM fiber and binder volume fractions in the tip zone (Fig. 5). Also, in successive winding of layers the tension of preceding layers decreases thus giving rise to process-related residual stresses. Therefore, during the winding one should control not only the tension force but the center-to-center distance as well.

Thus, the foregoing considerations outline the extent of a system of mathematical and experimental means for the stress analysis and design of the proposed jointing modes for high-loaded composite structural components. 


\section{CONCLUSIONS}

1. Based on the study of special features of composite materials and experience of their applications in aircraft structures, the design principles for metal-composite joints have been substantiated and novel design and engineering solutions for their implementation have been proposed.

2. The extent of theoretical and experimental means that would be required for the stress analysis and design of joints has been outlined.

3. The static strength test results for the proposed DES have been provide which demonstrate these solutions to be highly efficient and advisable for further engineering applications in various fields.

\section{REFERENCES}

1. V. T. Chmil', V. A. Ivanitskii, E. I. Poznyakov, et al., "The influence of some design and engineering factors on the strength of riveted and adhesively bonded joints of carbon fiber reinforced plastics," in: II Interindustry School of Structural Design [in Russian], Abstracts of Papers, Kharkov (1980), p. 42.

2. V. V. Vorobei and O. S. Sirotkin, Jointing of Composite Structures [in Russian], Mashinostroenie, Leningrad (1985).

3. A. D. Il'ina, "Input strength characteristics of composites for the design of mechanical joints," in: Design, Stress Analysis, and Testing of Composite Structures [in Russian], TsAGI, Moscow (1979), Issue 7, pp. 5660.

4. I. E. Leonova and M. I. Semin, "An experimental study of strength anisotropy in bolted joints of composite laminates with variable geometrical and design parameters," Mekh. Kompozit. Mater., No. 2, 268-272 (1990).

5. Ch. E. S. Ueng and K. D. Zhang, "Strength assessment of mechanical joints in composite laminate structures," Aérokosm. Tekhnika, No. 4, 29-33 (1986).

6. C. A. M. De Koning and N. H. M. Dreumel, "Mechanical jointing in aramid fibre composites: an experimental study," J. Aircraft, 20, No. 1, 1-16 (1983).

7. L. J. Hart-Smith, "Bonded-bolted composite joint," J. Aircraft, 22, No. 11, 993-1000 (1985).

8. J. R. Vinson, "Mechanical testing of polymer composites," Polymer Eng. Science, 29, No. 19, 1332-1339 (1989).

9. V. A. Matvienko and I. V. Burau, "Analysis of the state-of-the-art of and prospects for the design and engineering improvement of polymer composite joints," in: Proc. Workshop on Prospects for the Development of Manufacturing Processes for Composite Structures [in Russian], NIAT, Moscow (1986), pp. 3-12.

10. V. A. Reznikov and I. D. Samoletov, "Machining accuracy of holes in combined assemblies containing carbon fiber reinforced plastic," in: Proc. Workshop on Prospects for the Development of Manufacturing Processes for Composite Structures [in Russian], NIAT, Moscow (1986), pp. 19-25.

11. O. S. Sirotkin, "Design and engineering of jointing composite structural components," Plast. Massy, No. 3, 57-61 (1976).

12. A. D. Il'ina and Yu. S. Il'in, "High-strength composite joints," in: Design, Stress Analysis, and Testing of Composite Structures [in Russian], TsAGI, Moscow (1979), Issue 7, pp. 42-49.

13. V. P. Grigor'ev, O. S. Sirotkin, V. F. Gromov, et al., "A new method of riveted jointing of composite structures," Plast. Massy, No. 3, 71-73 (1976).

14. A. L. Abibov, V. V. Vasil'ev, V. F. Kut'inov, et al., "Design, stress analysis and testing of joints in composite structures," in: Design, Stress Analysis, and Testing of Composite Structures [in Russian], TsAGI, Moscow (1973), Issue 1, pp. 190-196.

15. O. S. Sirotkin, "Design of jointing for composite structural composites," Izv. Vuzov, Ser. Mashinostroenie, No. 2, 30-33 (1978).

16. M. S. Artyukhov, B. N. Anufriev, V. V. Vorobei, et al., "Pinned jointing of polymer composites," Plast. Massy, No. 3, 66-68 (1976). 
17. B. A. Dogmatyrskii, O. N. Sirotkin, and A. I. Yarkovets, Bolted and Riveted Jointing of Glass Fiber Reinforced Plastic Structural Components [in Russian], MAI, Moscow (1972).

18. M. I. Akulin, T. M. Davydova, A. N. Kirillin, et al., "Peculiarities of riveted/adhesive bonding processes for composite materials," in: Design, Stress Analysis, and Testing of Composite Structures [in Russian], TsAGI, Moscow (1979), Issue 7, pp. 60-65.

19. Yu. S. Tsarakhov, Design of Joints for Aircraft Composite Structural Components. Manual [in Russian], MFTI, Moscow (1980).

20. O. S. Sirotkin, V. V. Litvinov, and V. I. Grishin, Technology and Mechanics of Joints [in Russian], Arktika, Moscow (2000).

21. V. S. Bogolyubov, Forming Fixtures Made of Polymer Materials [in Russian], Mashinostroenie, Moscow (1979).

22. O. S. Sirotkin, G. P. Zaitsev, K. V. Kaikov, et al., "Contact interaction in a metal-to-composite pin joint in the presence of crack-type flaws," Mekh. Kompozit. Mater., No. 1, 100-104 (1978).

23. V. A. Blagov, A. P. Kolmychov, V. N. Kobelev, et al., Light-Weight Plastic Structures for Shipbuilding [in Russian], Sudostroenie, Leningrad (1969).

24. H. Dörner, Drei Welten - ein Leben, Heiner Dörner, Heilbronn (1995).

25. L. Brautman and R. Krock (Eds.), Composite Materials. In 8 volumes. Vol. 7: Analysis and Design of Structures [Russian translation], Mashinostroenie, Moscow (1978).

26. L. Brautman and R. Krock (Eds.), Composite Materials. In 8 Volumes. Vol. 8: Analysis and Design of Structures [Russian translation], Mashinostroenie, Moscow (1978).

27. L. Brautman and R. Krock (Eds.), Modern Composite Materials [Russian translation], Mir, Moscow (1978).

28. L. G. Belozerov, A Study of Performance of Composite Structural Components with Controlled Properties [in Russian], TsAGI, Moscow (1978), Issue 1913, pp. 13-26.

29. V. E. Gaidachuk and Ya. S. Karpov, "Kai Scientific School for the development of high-performance polymer composite structures for aircraft applications," Technol. Cestum, No. 2, 81-83 (1999).

30. A. S. Karpov, "Principles of design of jointing aircraft high-loaded composite components," in: Issues of Design and Manufacture of Aircraft Structures [in Russian], Collected Papers, Kai, Kharkov (2001).

31. A. S. Karpov, "Scientific foundations for solving the problems of jointing aircraft high-loaded composite structural components," Technol. Cestum, No. 3, 36-40 (2000).

32. V. E. Gaidachuk, S. P. Klimenko, A. S. Karpov, et al., A Propeller Blade Made of Composite Material [in Russian], USSR Inventor's Certificate No. 1215271, MKI V64S 11/06. Publ. 5 March 1984.

33. V. E. Gaidachuk, A. S. Karpov, A. V. Korzhenevskii, et al., A Method of Jointing Fiber Reinforced Composite Components [in Russian], USSR Inventor's Certificate No. 1121867, MKI V64S 1/12. Publ. 10 January 1983.

34. V. E. Gaidachuk, A. S. Karpov, V. F. Kut'inov, et al., A Joint Assembly of Dissimilar Materials [in Russian], USSR Inventor's Certificate No. 1110071, MKI V64S 1/12. Publ. 7 January 1983.

35. A. V. Korzhenevskii, S. I. Vesel'skii, V. A. Makarenko, et al., "A study of bearing strength of composite materials," in: Issues of Design and Manufacture of Aircraft Structures [in Russian], Collected Papers, Kai, Kharkov (2001), pp. 112-116.

36. A. S. Karpov, V. A. Makarenko, and V. G. Marchenko, "A study of anisotropy of composite material resistance to crushing by fastening elements," in: Stress Analysis and Design of Aircraft Structures [in Russian], Collected Papers, Kai, Kharkov (1989), pp. 82-91.

37. A. L. Rabinovich and L. D. Avrasin, "On mechanical characteristics of some plastics in relation to strength of bolted and riveted joints," in: Glass Reinforced Plastics and Other Structural Materials [in Russian], Mashinostroenie, Moscow (1960), pp. 25-32. 